inserted directly into the tissues, or placed inside a cavity as in the case of treatment of the cervix uteri. In Part I, separate chapters are devoted to each of these three methods of using radium and there are numerous worked examples on which the student can practise his skill in the rules.

Part II is devoted to the physical and mathematical basis for the rules and to a discussion of the uniformity of dose achieved by their use. In several cases of volume implantation, the isodose charts obtainable under idealized conditions are given. It is, perhaps, a pity that the method of presenting the results in the form of isodose charts is not used more extensively throughout the book. Finally, a chapter is added on the use of radiographs taken immediately after the implantation of the radium as a check on the accuracy of the implant and on the dosage distribution achieved.

The Editor is to be congratulated on having welded this series of papers by many different authors into a unified volume. The radiotherapist who is starting to use radium clinically will find this an essential reference book and physicists will be grateful not only for Part II but also for the fact that Part I ought to enable the radiotherapist to do a great many of his own calculations. The tables at the back fold out conveniently so that they can be consulted alongside the text.

J.W.B.

\section{HORMONES AND VITAMINS}

By G. A. Stephens, M.P.S. George Newnes' 1947. Price 215.

In the author's words this book is intended 'to provide a readily accessible compilation of chemical and clinical information on Hormones and Vitamins, to facilitate dispensing of them by the pharmacist, and the prescribing of them by both physicians and surgeons.'

An up-to-date book of this type is badly needed and Mr. Stephens succeeds admirably. The facts are set down straightforwardly and concisely. Details of the chemistry of hormones and vitamins are stated as simply and briefly as possible with appropriate comments as to their chemical relationship and mode of action. The effective dosage is clearly stated and when this can be measured in units or by weight the equivalent values are given.

Although Mr. Stephens is not medically qualified his brief descriptions of the clinical states due to deficiency of hormones and vitamins are adequate, and in most cases he distinguishes clearly between those conditions due to proven deficiencies and those where the indications for treatment are equivocal.

Occasionally he appears to accept too readily statements as to the clinical effects of certain substances ; for example most medical men would disagree with the optimistic views concerning the effect of nicotinic acid in angina pectoris (page 224).
Though these claims are always supported by references of medical literature, their acceptance is at times uncritical. A more detailed account of the dosage and methods of administration of adrenalin for asthma (including the minim a minute method advocated by the late Sir Arthur Hurst) and of the indications and dosage for subcutaneous implantations of testosterone and doca would be helpful. On page 192 ' hypothrombinaemia' is repeatedly mis-spelt.

These criticisms are, however, of minor importance. This book is of a high standard, it is handy in size and well produced. A useful glossary of medical terms and the composition of various proprietary preparations is included. It can be strongly recommended as an excellent reference book for senior medical students and practitioners

R.S.B.P.

\section{ILLUSTRATIONS OF REGIONAL ANATOMY}

By E. B. Jamieson, M.D. 7th Edition. In seven sections, sold singly. E. \& S. Livingstone, Ltd. 1947. In one bound volume, price $75 \mathrm{~s}$.

Once more there appears a new edition of these magnificent illustrations of anatomy. They form the ideal companion to the standard textbooks on the subject and their accuracy and clarity has not been equalled in any other similar publication.

Now that they are published in full colour on a very fine quality paper they are extremely good value for the price and it is unlikely that any medical student could afford not to buy them. To the lecturer in surgery they are most useful in perfecting his blackboard teaching. To the surgeon, they are also most acceptable since he can detach those plates to which he wishes to refer before operating on a part of the body with which he is not entirely familiar, and take them along to the operating theatre. It is probable that the medical student would welcome binding covers which were resistant to grease since these manuals often supplement his study in the dissecting room.

H.T.

\section{TUBERGULOSIS INDEX AND ABSTRAGTS OF GURRENT LITERATURE}

December, 1947. Vol. 2, 4. N.A.P.T. Tavistock House North. Subscription one guinea per year.

This little quarterly journal gives a complete list of current articles on all aspects of tuberculosis.

It is kept remarkably up to date, and the world literature is well surveyed. A more elaborate classification than previously has been used in the current number, with a good cross index, which makes for easy reference.

For the busy physician or research worker, this journal is an invaluable key to the specialized literature on tuberculosis.

C.P.H. 